\title{
Factors influencing the presence of Candida dubliniensis and other non-albicans species in patients with oral lichen planus: a retrospective observational study
}

\author{
Florian Molkenthin $^{1}$ (D) $\cdot$ Moritz Hertel $^{1} \cdot$ Konrad Neumann $^{2} \cdot$ Andrea Maria Schmidt-Westhausen $^{1}$
}

Received: 19 January 2021 / Accepted: 20 May 2021 / Published online: 18 June 2021

(c) The Author(s) 2021

\begin{abstract}
Objectives The epidemiologic distribution of non-albicans species in the oral cavity of oral lichen planus (OLP) patients remains uncertain. Therefore, the aim of this study was to identify factors associated with the presence of $C$. dubliniensis and other non-albicans species. Furthermore, independent risk factors for Candida superinfection in OLP should be identified. Material and methods Epidemiologic data and microbiological findings from 268 symptomatic OLP patients who underwent continuous oral swab culture over a 5-year period (2015-2019) were retrospectively reviewed. Candida species identification and semi-quantification were obtained by culture on CHROMagar Candida, followed by matrix-assisted laser desorption/ ionization time-of-flight mass spectrometry (MALDI-TOF MS).

Results C. albicans was the most frequently isolated species (72.3\%), followed by C. glabrata (7.3\%), C. dubliniensis (5.8\%), C. krusei and $C$. parapsilosis (both 2.6\%). The presence of $C$. dubliniensis was significantly associated with tobacco smoking. Other non-albicans spp. were significantly more often detected in patients using removable dentures. Increasing age and the intake of psychotropic drugs were identified as independent risk factors of Candida superinfection in OLP.

Conclusion In OLP patients, certain local and systemic factors increase the risk of carrying potentially drug-resistant Candida species and the development of Candida superinfection of OLP lesions.

Clinical relevance Due to the frequent detection of non-albicans species in OLP, resistance or at least reduced sensitivity to azole antifungals should be expected, especially in smokers and patients using removable dentures. In the case of oral complaints, a superinfection with Candida should be considered, whereby older patients and patients taking psychotropic drugs have an increased risk for oral infection with Candida.
\end{abstract}

Keywords Candida $\cdot$ Oral lichen planus $\cdot$ Non-albicans species $\cdot$ Oral candidiasis

\section{Introduction}

Due to the frequent and preventive use of antifungal drugs in immunocompromised patients and due to more precise and faster methods for the identification of Candida species, the emergence of non-albicans species (spp.) has been observed in recent years [1]. Although these species typically lack

Florian Molkenthin

florian.molkenthin@charite.de

1 CharitéCentre 3, Department of Periodontology, Oral Medicine and Oral Surgery, Charité - Universitätsmedizin Berlin, Aßmannshauser Str. 4, 14197 Berlin, Germany

2 Institute of Medical Biometrics and Clinical Epidemiology, Charité - Universitätsmedizin Berlin, Charitéplatz 1, 10117 Berlin, Germany the range of virulence factors found in $C$. albicans, they have come to prominence due to their frequent intrinsic or acquired resistance to azole antifungals [2, 3]. A paradigm of this selective process could be the emergence of $C$. dubliniensis [4]. This species shares many phenotypic characteristics with $C$. albicans, including the ability to produce hyphae and chlamydospores, features previously associated only with $C$. albicans [5]. Despite the phenotypic similarities, it is less pathogenic and less frequently isolated from the oral cavity [6]. However, C. dubliniensis is increasing in clinical significance as this species is potentially less susceptible or resistant to fluconazole, although mostly after extensive prophylaxis/therapy with this drug [7]. Furthermore, it has been demonstrated that fluconazole resistance in C. dubliniensis is easily inducible in vitro and that the adherence of 
this organism to epithelial cells increases in the presence of fluconazole $[8,9]$.

Oral mucosal diseases, such as oral lichen planus (OLP), may be influenced by the presence of Candida spp. [10-12]. OLP is a chronic inflammatory disease of autoimmune origin that affects between 0.9 and $2.6 \%$ of the population [13]. Several Candida species have been isolated from the oral cavity of OLP patients, with $C$. albicans being the most common $[12,14,15]$. However, it has been shown that nonalbicans species are more frequently present in OLP patients compared to healthy subjects [16].

A challenge in the treatment of OLP is the presence or development of Candida superinfection, which makes antimycotic therapy necessary. Infections with Candida species can lead to both exacerbation and obscuration of the clinical features of OLP, as both conditions may be associated with burning pain and erythematous lesions [17]. In addition, hyphal invasion is a potential risk factor for malignant transformation through the production of carcinogenic metabolites of Candida such as nitrosamines and acetaldehyde $[18,19]$.

The presence of non-albicans species in patients with oral mucosal alterations and the respective clinical impact, especially of $C$. dubliniensis, remain partly unknown. In order to initiate an adequate antifungal therapy in OLP patients while avoiding potential problems related to microbial resistance, the aim of this study was $(i)$ to determine factors associated with the presence of $C$. dubliniensis and other non-albicans species and (ii) to identify independent risk factors for the presence of Candida superinfection of OLP lesions.

\section{Material and methods}

\section{Study design}

A retrospective, observational and cross-sectional study was conducted at the Department of Periodontology, Oral Medicine and Oral Surgery of the Charité - Medical University Berlin. Microbiological findings and records of symptomatic OLP patients treated at the department between 01 January 2015 and 31 December 2019 (5 years) were eligible.

All patients (i) with the clinical and/or histological diagnosis of oral lichen planus (ii) and who underwent an oral swab culture testing for the presence of Candida spp. were included. The clinical diagnostic criteria for OLP included the presence of bilateral, more or less symmetrical lesions, the presence of a reticular pattern with grayish-white lines (Wickham striae) and papular, plaque-like, erythematous, erosive and bullous variants as subtypes. Exclusion criteria comprised all patients (i) with clinical/histological mucogingival disease other than OLP, (ii) under antifungal (including chlorhexidine) or antibiotic therapy, (iii) under systemic immunosuppressive therapy, human immunodeficiency virus (HIV)-positive patients and (iv) patients with a history of anaemia, and radiation therapy or surgery for head and neck malignancy.

During the above-mentioned period, all patients underwent an intraoral examination by an oral medicine specialist. Demographic data including age and gender, clinical features of OLP, current use of topical immunosuppressive drugs, concomitant diseases, medication taken, presence of removable dentures and complete smoking history (i.e. daily consumption and pack years) were documented. The data were recorded using a standardized data entry form. Based on this information, a de-identified database was created.

\section{Diagnosis of oral candidiasis}

Superinfection with Candida species was diagnosed based on clinical signs (loss of lingual papillae, redness and fissures on the tongue, erythematous oral mucosa and white, removable plaques) and/or symptoms (loss of taste, burning, pain) associated with at least moderate growth of one Candida species in culture. Accordingly, these patients received local antifungal therapy with nystatin ointment or amphotericin B troches for at least 3 weeks.

\section{Yeast sampling and culture}

Specimens were obtained by swabbing of the affected OLP lesions with a nylon-flocked sample collection swab (ESwab ${ }^{\mathrm{TM}}$, COPAN Diagnostics Inc., USA). After the swab was taken, the samples were immediately transferred into a transport tube with $1 \mathrm{ml}$ Amies medium (COPAN Diagnostics Inc., USA) and sent to the laboratory within $24 \mathrm{~h}$ for microbiological diagnostics. Samples were fractionally spread on the culture media. Each sample was plated on Sabouraud Dextrose Agar (SDA with chloramphenicol and gentamicin, $\mathrm{pH}=6.8 \pm 0.2$ ) and on CHROMagar ${ }^{\mathrm{TM}}$ Candida (Becton Dickinson, USA). The SDA plate was incubated at $28^{\circ} \mathrm{C}$, and the CHROMagar ${ }^{\mathrm{TM}}$ plate at $36^{\circ} \mathrm{C}$ for 4 days each. If no growth occurred after 4 days, the incubation time was extended to 7 days. A presumptive assignment according to the growth on CHROMagar ${ }^{\mathrm{TM}}$ Candida was followed by the exact species identification. Samples from pre-cultured single colonies were analyzed by matrix-assisted laser desorption/ionization and time-of-flight mass spectrometry (MALDITOF MS, Vitek $\odot$ MS, bioMérieux, France) or by biochemical identification with the Vitek $\odot 2$ ID-card (bioMérieux, France). In order to distinguish between $C$. albicans and $C$. dubliniensis the latex agglutination test (BICHRO-DUBLI FUMOUZE@, Biosynex, France) was performed after growth of green colonies on CHROMagar ${ }^{\mathrm{TM}}$ Candida. A semi-quantitative estimation of fungal growth was carried out, and the following classification was used: 
sporadic growth: $\leq 10$ colony forming units $(\mathrm{CFU})$ in the first section; low growth: $>10 \mathrm{CFU}$ and growth in the first section; moderate growth: growth up to the second section; abundant growth: growth up to the third section.

\section{Statistical analysis}

For all categorical variables absolute and relative frequencies were given. Continuous variables were described by mean value and standard deviation. Furthermore, Pearson's Chi-square test (or Fisher's exact test if one of the expected cell frequencies was below 5) was used to determine whether patient characteristics were associated with the detection of C. dubliniensis or other non-albicans species, and with the presence of Candida superinfection. Mean values of continuous variables were compared using Student's $t$-test. All variables with $p$-values $\leq 0.2$ in the simple bivariate analysis, including demographic, local, systemic and lifestyle factors, were included in binomial logistic regression models. We did not apply model selection algorithms such as backward or forward selection. The dependent variables of three logistic regression models were the presence of $C$. dubliniensis and non-albicans species, respectively, and the occurrence of Candida superinfection of OLP.

All statistical tests were performed two-sided and a $p$-value of $\leq 0.05$ was considered significant. In this exploratory study, all $p$-values are unadjusted. Statistical analysis was performed using IBM ${ }^{\circledR}$ SPSS ${ }^{\circledR}$ Version 25.0.

\section{Results}

\section{Study population}

In total, 268 patients met the inclusion and exclusion criteria (210 females, mean age: $64.9 \pm 11.7$ years; 58 males, mean age: $60.2 \pm 13.4$ years). Demographic, clinical, and anamnestic characteristics of the patients are presented in Table 1. The demographic data and data regarding the clinical characteristics and therapy of OLP were completely available in all patients. Data on concomitant diseases were missing in two patients and data on medication, prosthetics and smoking history were missing in three patients, respectively. The mean age of the patients was $63.9 \pm 12.2$ years (range: 26-88), with the mean age of female patients being significantly higher than that of male patients $(p=0.019)$. In addition, female patients suffered significantly more frequently from hypothyroidism $(p<0.001)$, autoimmune diseases (except lichen planus; $p=0.025$ ) and asthma/COPD ( $p=0.047)$ compared to male patients. Regarding the clinical features of OLP, 112 patients (41.8\%) showed erosive or ulcerative lesions at the time of examination. In addition, 33 patients (12.3\%) had extraoral manifestations of lichen planus, while women were significantly more likely to have extraoral involvement $(p=0.020)$. In 142 of 268 cases (53.0\%), a biopsy was taken, and the clinical diagnosis was confirmed by histopathological examination. In all other cases, a biopsy was not performed due to the typical pattern of OLP. Within the last 4 weeks before the examination, 42 of 268 patients (15.7\%) applied topical steroids for a maximum of 14 consecutive days. Regarding drug history, 140 of 265 patients $(52.8 \%)$ were treated with antihypertensives (ACE inhibitors, AT2 receptor blockers, beta-receptor blockers, diuretics and calcium antagonists). Among them, 57 patients $(40.7 \%)$ took two or more antihypertensive drugs. Thirty-one of 265 patients (11.7\%) regularly took psychotropic drugs (antidepressants, antipsychotics, antiepileptic drugs, anxiolytics, and hypnotics), with antidepressants being the most frequent $(80.6 \%)$.

\section{Microbiological results}

In 160 of 268 OLP patients (59.7\%), a total of 191 yeasts were isolated. The spectrum of isolated Candida species is shown in Fig. 1. Among all 191 isolates, C. albicans was the most frequent species (72.3\%). Thirteen different non-albicans species accounted for $27.7 \%$. The most common nonalbicans species were C. glabrata (7.3\%), C. dubliniensis (5.8\%), C. krusei and C. parapsilosis (both 2.6\%). Species known to be less susceptible or resistant to azole antifungals (C. glabrata, C. krusei and C. dubliniensis) accounted for $15.7 \%(30 / 191)$ of all isolates and 56.6\% (30/53) of nonalbicans species. In 22 samples, more than one Candida species was found (mixed cultures). C. albicans was isolated as monoculture in 117 patients. C. dubliniensis was isolated from oral samples of 11 patients, in $7 / 11$ cases as monoculture and in 4/11 cases co-isolated as mixed culture with $C$. albicans. In 36 patients non-albicans species other than $C$. dubliniensis were isolated, with $16 / 36$ cases being mixed cultures consisting of more than one species (with or without $C$. albicans).

\section{Factors associated with the presence of $C$. dubliniensis}

Cross-tabulation analysis revealed that the presence of $C$. dubliniensis was not significantly associated with gender, clinical characteristics of OLP, current use of topical steroids, the presence of removable dentures, diabetes mellitus, other autoimmune diseases, use of antihypertensive drugs, psychotropic drugs, inhaled steroids or proton pump inhibitors. The mean age of patients with $C$. dubliniensis was significantly lower than that of patients with $C$. albicans $(p=0.039)$. Furthermore, tobacco smoking was significantly associated with colonization/infection by $C$. dubliniensis $(p<0.001)$ (Table 2). 
Table 1 Demographic, clinical and anamnestic characteristics of OLP patients
Fig. 1 Distribution of Candida isolates from the oral cavity of OLP patients

\begin{tabular}{|c|c|c|c|c|}
\hline Feature $(n)$ & $\begin{array}{l}\text { Total } \\
\text { No. }(\%)\end{array}$ & $\begin{array}{l}\text { Female } \\
\text { No. (\%) }\end{array}$ & $\begin{array}{l}\text { Male } \\
\text { No. (\%) }\end{array}$ & $P^{\mathrm{a}}$ \\
\hline Total & $268(100)$ & $210(78.4)$ & $58(21.6)$ & - \\
\hline Mean age (SD) & $63.9( \pm 12.2)$ & $64.9( \pm 11.7)$ & $60.2( \pm 13.4)$ & 0.019 \\
\hline \multicolumn{5}{|l|}{ Clinical features (268) } \\
\hline Erosive & $112(41.8)$ & $88(41.9)$ & $24(41.4)$ & 0.943 \\
\hline Non-erosive & $156(58.2)$ & $122(58.1)$ & $34(58.6)$ & \\
\hline Extraoral involvement & $33(12.3)$ & $31(14.8)$ & $2(3.4)$ & 0.020 \\
\hline \multicolumn{5}{|l|}{ Treatment (268) } \\
\hline Topical steroids & $42(15.7)$ & $37(17.6)$ & $5(8.6)$ & 0.095 \\
\hline \multicolumn{5}{|l|}{ Removable denture (265) } \\
\hline Present & $63(23.8)$ & $51(24.6)$ & $12(20.7)$ & 0.532 \\
\hline \multicolumn{5}{|l|}{ Concomitant disease (266) } \\
\hline Hypertension & $149(56.0)$ & $119(57.2)$ & $30(51.7)$ & 0.457 \\
\hline Hypothyroidism & $76(28.6)$ & $72(34.6)$ & $4(6.9)$ & $<0.001$ \\
\hline Diabetes mellitus & $36(13.5)$ & $29(13.9)$ & $7(12.1)$ & 0.712 \\
\hline Autoimmune disease & $44(16.5)$ & $40(19.2)$ & $4(6.9)$ & 0.025 \\
\hline Asthma/COPD & $28(10.5)$ & $26(12.5)$ & $2(3.4)$ & 0.047 \\
\hline Mental disorders & $30(11.3)$ & $21(10.1)$ & $9(15.5)$ & 0.299 \\
\hline Allergies & $88(33.1)$ & $71(34.1)$ & $17(29.3)$ & 0.490 \\
\hline \multicolumn{5}{|l|}{ Medication (265) } \\
\hline Antihypertensives & $140(52.8)$ & $111(53.6)$ & $29(50.0)$ & 0.625 \\
\hline NSAID & $41(15.5)$ & $33(15.9)$ & $8(13.8)$ & 0.689 \\
\hline Inhaled steroids & $14(5.3)$ & $12(5.8)$ & $2(3.4)$ & 0.741 \\
\hline Psychotropic drugs & $31(11.7)$ & $23(11.1)$ & $8(13.8)$ & 0.574 \\
\hline Proton pump inhibitors & $26(9.8)$ & $22(10.6)$ & $4(6.9)$ & 0.398 \\
\hline \multicolumn{5}{|l|}{ Lifestyle (265) } \\
\hline Smoker & $40(15.1)$ & $33(15.9)$ & $7(12.1)$ & 0.466 \\
\hline Former smoker & $55(20.8)$ & $44(21.3)$ & $11(19.0)$ & 0.704 \\
\hline
\end{tabular}

Complete data for concomitant diseases were available from 266 patients and for medication, presence of removable dentures, and smoking from 265 patients

$S D$ standard deviation; $C O P D$ chronic obstructive pulmonary disease; NSAID non-steroidal anti-inflammatory drugs

${ }^{\text {a }}$ Referring to inter-gender comparison

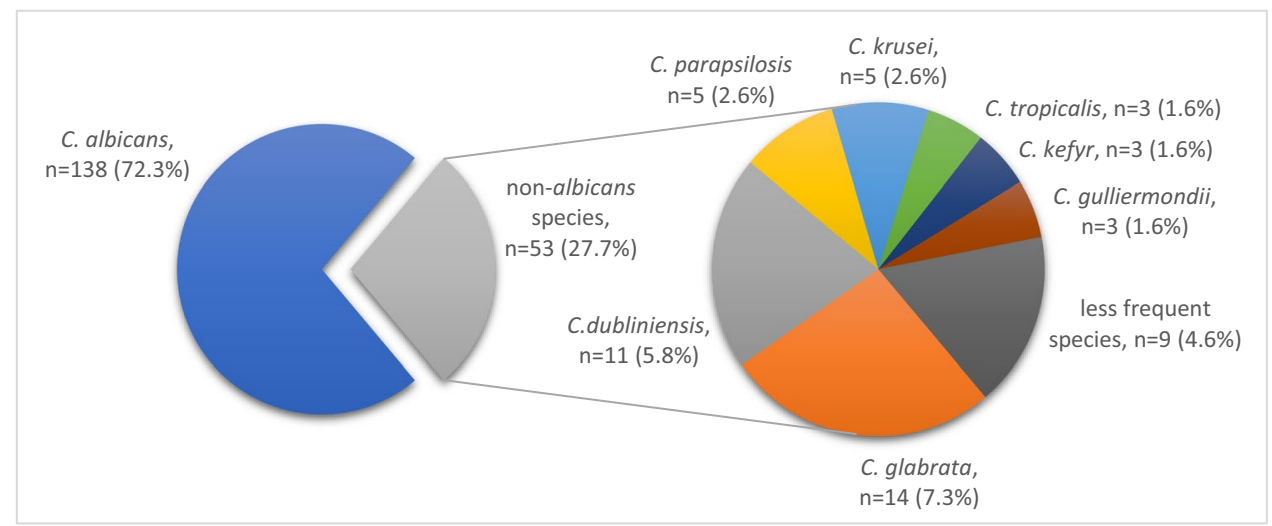

A logistic regression model, including age, asthma/ COPD, inhalative steroids and tobacco smoking showed that only tobacco smoking significantly increased the odds to carry $C$. dubliniensis ( $p=0.001, \mathrm{OR}=10.51$ (95\% CI [2.52, 
Table 2 Comparison of factors influencing the detection of certain Candida species

\begin{tabular}{|c|c|c|c|c|c|}
\hline Influencing factors & $\begin{array}{l}\text { Candida albi- } \\
\text { cans }(n=117) \\
\text { No. }(\%)\end{array}$ & $\begin{array}{l}\text { Candida dublin- } \\
\text { iensis }(n=11) \\
\text { No. }(\%)\end{array}$ & $P^{\mathrm{a}}$ & $\begin{array}{l}\text { Other non-albi- } \\
\text { cans spp. }(n=36) \\
\text { No. }(\%)\end{array}$ & $P^{\mathrm{a}}$ \\
\hline \multicolumn{6}{|l|}{ Demography } \\
\hline Mean age (SD) & $66.2( \pm 10.5)$ & $58.9( \pm 16.1)$ & 0.039 & $69.1( \pm 9.5)$ & 0.129 \\
\hline Gender (male) & $24(20.5)$ & $0(0)$ & - & $6(16.7)$ & 0.611 \\
\hline \multicolumn{6}{|l|}{ Local } \\
\hline Erosive OLP & $56(47.9)$ & $4(36.4)$ & 0.465 & $13(36.1)$ & 0.215 \\
\hline Topical steroids & $18(15.4)$ & $2(18.2)$ & 0.682 & $7(19.4)$ & 0.565 \\
\hline Inhaled steroids & $6(5.2)$ & $2(18.2)$ & 0.145 & $2(5.6)$ & 1.000 \\
\hline Removable denture & $28(24.3)$ & $4(36.4)$ & 0.469 & $21(58.3)$ & $<0.001$ \\
\hline \multicolumn{6}{|l|}{ Systemic } \\
\hline Hypothyroidism & $38(32.8)$ & $3(27.3)$ & 1.000 & $9(25.0)$ & 0.379 \\
\hline Diabetes mellitus & $21(18.1)$ & $0(0)$ & - & $7(19.4)$ & 0.856 \\
\hline Autoimmune disease & $20(17.2)$ & $3(27.3)$ & 0.418 & $11(30.6)$ & 0.083 \\
\hline Asthma/COPD & $13(11.2)$ & $3(27.3)$ & 0.144 & $3(8.3)$ & 0.763 \\
\hline \multicolumn{6}{|l|}{ Drug-induced ${ }^{b}$} \\
\hline Antihypertensives & $70(60.9)$ & $5(45.5)$ & 0.320 & $20(55.6)$ & 0.571 \\
\hline Psychotropic drugs & $18(15.7)$ & $2(18.2)$ & 0.686 & $6(16.7)$ & 0.884 \\
\hline Proton pump inhibitors & $13(11.3)$ & $1(9.1)$ & 1.000 & $6(16.7)$ & 0.397 \\
\hline \multicolumn{6}{|l|}{ Lifestyle } \\
\hline Smoker & $14(12.2)$ & 7 (63.6) & $<0.001$ & $2(5.6)$ & 0.360 \\
\hline Former smoker & $27(23.5)$ & $1(9.1)$ & 0.453 & $8(22.2)$ & 0.876 \\
\hline
\end{tabular}

Classification: C. albicans monoculture, $C$. dubliniensis, and other non-albicans species (both with and without $C$. albicans). Complete data for concomitant diseases were available from 116 patients and for medication, presence of a removable denture and smoking from 115 patients with $C$. albicans

$S D$ standard deviation; $O L P$ oral lichen planus; $C O P D$ chronic obstructive pulmonary disease

${ }^{\text {a }}$ Colonisation/infection with $C$. albicans as reference

${ }^{\mathrm{b}}$ Drugs with a high level of evidence for causing hyposalivation
43.83]). The logistic regression model was statistically significant, $\chi^{2}(4)=18.13, p=0.001$. The Hosmer-Lemeshow test indicated a good model fit $\left(\chi^{2}(7)=4.99, p=0.662\right)$. None of the correlations between predictor variables were high (Pearson correlation $r<0.70$ ), indicating that multicollinearity was not a confounding factor in the analysis.

\section{Factors associated with the presence of other non-albicans species}

Cross-tabulation and $t$-test analyses revealed no statistically significant associations between sex, age, clinical forms of OLP, current use of topical steroids, diabetes mellitus, other autoimmune diseases, use of antihypertensive drugs, psychotropic drugs, inhaled steroids or proton pump inhibitors, and smoking with the presence of non-albicans species other than C. dubliniensis. Compared to C. albicans, patients who wore a removable denture were significantly prone to colonization/infection by other non-albicans species (with or without $C$. albicans) $(p<0.001)$. Patients with other autoimmune diseases (than lichen planus) also tended to be more frequently colonized/infected with other non-albicans species, although this was not statistically significant $(p=0.083)$ (Table 2).

The binomial logistic regression analysis, including age, autoimmune diseases and removable dentures confirmed, that only the presence of removable dentures was statistically significant $(p=0.001)$, increasing the likelihood for the presence of non-albicans species other than C. dubliniensis in OLP patients ( $\mathrm{OR}=4.19,95 \%$ CI $[1.78,9.88])$. The logistic regression model was statistically significant, $\chi^{2}(3)=15.92, p=0.001$. The Hosmer-Lemeshow test indicated a good model fit $\left(\chi^{2}(8)=1.61, p=0.991\right)$. Correlations between predictor variables were low (Pearson correlation $r<0.40$ ), indicating that multicollinearity was not a confounding factor in the analysis.

\section{Risk factors for Candida superinfection}

In total, in 97/268 patients (36.2\%), superinfection of OLP with Candida species was diagnosed. Contingency table analysis showed no significant association of sex, current use of topical steroids, intake of proton pump inhibitors, inhaled 
steroids and positive smoking history with the occurrence of a Candida superinfection. The mean age of Candida superinfected patients was significantly higher than that of non-infected patients $(p<0.001)$. A statistically significant association was also found for the presence of removable dentures $(p=0.031)$, other autoimmune diseases $(p=0.041)$, the use of antihypertensive $(p=0.002)$ and psychotropic drugs $(p=0.002)$. Moreover, a significantly larger proportion of patients with erosive OLP than with non-erosive OLP suffered from Candida superinfection $(p=0.029)$. However, it was not possible to distinguish whether the erosive areas were the manifestation of lichen planus itself or the result of Candida infection. Therefore, this factor was not included into multivariate analysis. Patients with diabetes mellitus also suffered more frequently from Candida superinfection, although the difference was not statistically significant $(p=0.070)$ (Table 3).

The binomial logistic regression analysis, including the factors mentioned above, revealed that only two variables were statistically significant: age $(p=0.016)$ and the intake of psychotropic drugs $(p=0.008)$. Each year of life increased the odds of contracting Candida superinfection by $\mathrm{OR}=1.03$ (95\% CI [1.01, 1.06]), as did intake of psychotropic drugs
$(\mathrm{OR}=3.1595 \% \mathrm{CI}[1.36,7.29])$. The logistic regression model was statistically significant, $\chi^{2}(6)=28.19, p<0.001$. The Hosmer-Lemeshow test indicated a good model fit $\left(\chi^{2}(8)=4.96, p=0.762\right)$. Correlations between predictor variables were low (Pearson correlation $r<0.40$ ), indicating that multicollinearity was not a confounding factor in the analysis.

\section{Discussion}

In the Department of Periodontology, Oral Medicine and Oral Surgery of the Charite - Medical University Berlin, oral swabs are routinely used for the detection of Candida species in cases of suspected infections/superinfections. The advantages of this method are the site-specific isolation of viable cells and the easy application of this diagnostic tool. The disadvantage of this method is that it does not allow quantification but only a semi-quantitative estimation of microorganisms [20]. The most reliable diagnosis of Candida infection is the detection of hyphae invading the tissue [21]. Nevertheless, the oral swab technique was
Table 3 Comparison of predisposing factors for Candida superinfection in OLP

\begin{tabular}{|c|c|c|c|}
\hline Influencing factors & $\begin{array}{l}\text { No infection }(n=171) \\
\text { No. }(\%)\end{array}$ & $\begin{array}{l}\text { Superinfection }(n=97) \\
\text { No. }(\%)\end{array}$ & $P^{\mathrm{a}}$ \\
\hline \multicolumn{4}{|l|}{ Demography } \\
\hline Mean age (SD) & $61.7( \pm 12.8)$ & $67.6( \pm 10.1)$ & $<0.001$ \\
\hline Gender (male) & $39(22.8)$ & 19 (19.6) & 0.539 \\
\hline \multicolumn{4}{|l|}{ Local } \\
\hline Erosive OLP & $63(36.8)$ & $49(50.5)$ & 0.029 \\
\hline Topical steroids & $27(15.8)$ & $15(15.5)$ & 0.944 \\
\hline Inhaled steroids & $7(4.1)$ & $7(7.3)$ & 0.271 \\
\hline Removable denture & $33(19.5)$ & $30(31.3)$ & 0.031 \\
\hline \multicolumn{4}{|l|}{ Systemic } \\
\hline Hypothyroidism & $47(27.8)$ & $29(29.9)$ & 0.717 \\
\hline Diabetes mellitus & $18(10.7)$ & 18 (18.6) & 0.070 \\
\hline Autoimmune disease & $22(13.0)$ & $22(22.7)$ & 0.041 \\
\hline Asthma/COPD & $15(8.9)$ & $13(13.4)$ & 0.247 \\
\hline \multicolumn{4}{|l|}{ Drug-induced ${ }^{\mathrm{b}}$} \\
\hline Antihypertensives & 77 (45.6) & $63(65.6)$ & 0.002 \\
\hline Psychotropic drugs & $12(7.1)$ & $19(19.8)$ & 0.002 \\
\hline Proton pump inhibitors & $14(8.3)$ & $12(12.5)$ & 0.267 \\
\hline \multicolumn{4}{|l|}{ Lifestyle } \\
\hline Smoker & $27(16.0)$ & $13(13.5)$ & 0.595 \\
\hline Former smoker & $33(19.5)$ & $22(22.9)$ & 0.513 \\
\hline
\end{tabular}

Complete data for concomitant diseases were available from 266 patients and for medication, presence of removable dentures and smoking from 265 patients

$S D$ standard deviation; $O L P$ oral lichen planus; $C O P D$ chronic obstructive pulmonary disease

${ }^{a}$ No infection vs. superinfection

${ }^{\mathrm{b}}$ Drugs with a high level of evidence for causing hyposalivation 
used because the focus of this research was on the correct identification of Candida species and the clinical relevance of oral fungal infections in OLP.

Regarding the species spectrum, $C$. albicans was the predominant species in OLP patients. Non-albicans species accounted for $27 \%$ in total. This is consistent with recent findings by Arora and colleagues who also found a prevalence of $27 \%$ of non-albicans species in OLP patients in their prospective study [14]. Earlier studies reported a lower proportion of non-albicans species in OLP patients [10, 15, $22,23]$. This discrepancy may already be due to an emerging selective process or may be caused by differences in sample collection and methods for species identification. In agreement with other reports, the most frequently isolated nonalbicans species was $C$. glabrata [24, 25]. C. dubliniensis was the second most common non-albicans species in the present study. Although this species was first detected in the oral cavity of HIV-positive patients, several studies have reported the detection of $C$. dubliniensis in HIV-negative patients and healthy persons $[26,27]$. In the present study, none of the included patients was HIV positive. In recent years, $C$. dubliniensis has also been detected in the oral cavity of OLP patients, with and without oral candidiasis [14, 28-30]. These data and the present findings confirm the assumption that $C$. dubliniensis may also be a part of the oral microflora of patients with OLP.

Many local and systemic factors have been previously identified to enhance oral carriage of Candida species. These factors include, but not limited to, use of dentures, local steroids, tobacco smoking, reduced salivary flow, immunosuppressed states (such as HIV or secondary to age), endocrine disorders, receipt of xenogeneic drugs and broad-spectrum antibiotics [31-35]. In the present study, a number of such factors were analysed. To take all these factors into account, it was necessary to conduct multivariate analyses using binomial logistic regression.

So far, no study of patients with OLP has assessed the influence of certain factors on the composition of the yeast spectrum. Thus, the primary aim of this study was to identify factors associated with the detection of $C$. dubliniensis and other non-albicans species, respectively, compared to $C$. albicans. As a result, logistic regression analysis indicated a significant association between tobacco smoking and the presence of $C$. dubliniensis. Recent evidence supports these findings, as this study demonstrated that exposure of oral C. dubliniensis isolates to cigarette smoke condensate significantly enhanced in vitro adhesion traits and haemolysin production of these isolates [36]. All these attributes are considered essential virulence factors of Candida species, thereby increasing the pathogenicity of this species in the presence of cigarette smoke. Although $C$. albicans isolates showed a comparable increase of pathogenic attributes in the abovementioned study, in our investigation tobacco smoking was significantly more prevalent in $C$. dubliniensis carriers than in $C$. albicans carriers $(p<0.001)$. Smoking further reduces gingival exudate, resulting in a decrease in the number of leukocytes and immunoglobulins in the oral cavity [37]. Both are important factors in host defense to prevent Candida colonization [31]. In accordance with research by Al-Karawii et al., who reported local colonization-enhancing factors in $93 \%$ of the patients carrying $C$. dubliniensis, in the present study $91 \%$ of the patients carrying C. dubliniensis exhibited those factors that may enhance colonization/ infection by this species [28]. Kragelund et al. found this species to be overrepresented among OLP patients who were previously exposed to antimycotic drugs [30]. Since data regarding antimycotic treatment was only available between 2015 and 2019, it was not possible to verify the findings of Kragelund and coworkers in our study population. In conclusion, the diversity of the available data indicates a high variance in the epidemiological profile of $C$. dubliniensis, and further studies will be necessary to clarify its distribution pattern as well as the clinical implication of the presence of this yeast species.

Previous studies have reported high prevalences of nonalbicans species in oral specimens of denture wearers with or without denture stomatitis [38-40]. Consistent with this, logistic regression analysis in this series revealed that using removable dentures was significantly associated with the presence of non-albicans species (other than C. dubliniensis). It has been hypothesized that the frequent detection of non-albicans species in denture wearers may already reflect a selection process due to multiple antifungal treatments [40]. It has further been demonstrated that non-albicans species have a high cell surface hydrophobicity and a distinct ability to form biofilms compared to $C$. albicans, traits found to be beneficial for adherence to acrylic surfaces [25, $41,42]$. In addition, the mean age of patients carrying nonalbicans species was higher than that of patients carrying only $C$. albicans, although this association was not significant. Nevertheless, this trend was probable, as the frequency of denture use increases with age.

The secondary aim of the study was to determine independent factors that increase the risk of superinfection of OLP lesions with Candida species. Multivariate analysis identified increasing age and the use of psychotropic drugs as independent risk factors for Candida superinfection in the present cohort studied. Matching these findings, low unstimulated salivary flow rate and the intake of anxiolytics have already been found to be risk factors for oral fungal infections in OLP subjects [43]. Moreover, various psychotropic drugs such as antidepressants, antipsychotics, hypnotics and benzodiazepines, but also antiepileptic drugs (especially GABA agonists) show a high level of evidence for causing hyposalivation as an adverse drug reaction [44, 45]. In a large-scale study with more than 1200 participants, 
it was found that both increasing age and the use of psychotropic drugs were significantly associated with subjective dry mouth and an unstimulated salivary flow rate $<1 \mathrm{ml} / \mathrm{min}$ [46]. Reduced salivary flow rate, which may be age related, drug induced or due to an underlying disease, is a known predisposing factor for oral candidiasis [31]. Furthermore, it has been shown that the prevalence of oral candidiasis increases with age, although it is not clear whether age per se is a predisposing factor [47]. However, the present study was able to show through multivariate analysis that the likelihood of contracting Candida superinfection increased with each year of life.

Extrapolation of the study results may be affected by several limitations. Firstly, due to the retrospective nature of the present study, it was not conducted under controlled conditions and there is a possibility of missing data. This fact in mind and due to the small sample size of patients carrying C. dubliniensis, the results of this study should be understood as a trend. Furthermore, in this retrospective analysis neither Candida quantification nor testing of susceptibility to common antifungal drugs could be performed. Future and prospective studies might consider these aspects.

\section{Conclusion}

The results of this study indicate that $C$. albicans is the predominant species in OLP patients, but non-albicans species account for over $27 \%$ of all isolates. In smoking patients and subjects with removable dentures, $C$. dubliniensis and other non-albicans species were significantly more frequently detected than in non-smokers and patients without removable prostheses. Despite the limitations of the study, this should be considered in the antimycotic therapy of superinfected OLP lesions. In particular the use of azole antifungals in patients matching the criteria mentioned above should be conducted restrainedly due to potential drug resistance. Hence, yeast identification prior to antimycotic therapy appears to be recommendable, especially as resistance testing is usually not performed for oral candidiasis treatment. Furthermore, patients of increasing age and/or on psychotropic drugs require special attention in order to initiate appropriate therapy, i.e. early administration of antimycotic drugs.

Funding Open Access funding enabled and organized by Projekt DEAL. No external funding, apart from the support of the authors' institution, was received for this study.

\section{Declarations}

Ethical approval This article does not contain any studies with human participants or animals performed by any of the authors. All procedures retrospectively using data from humans were in accordance with the ethical standards of the institutional and/or national research committee and with the 1964 Helsinki declaration and its later amendments or comparable ethical standards. Formal approval was granted by the institutional ethical review committee of the Charité Universitätsmedizin Berlin (EA4/108/14). Data collected were pseudonymized at the stage of extraction from the patient's charts.

Informed consent For this type of study, formal consent is not required.

Conflict of interest The authors declare no conflict of interest.

Open Access This article is licensed under a Creative Commons Attribution 4.0 International License, which permits use, sharing, adaptation, distribution and reproduction in any medium or format, as long as you give appropriate credit to the original author(s) and the source, provide a link to the Creative Commons licence, and indicate if changes were made. The images or other third party material in this article are included in the article's Creative Commons licence, unless indicated otherwise in a credit line to the material. If material is not included in the article's Creative Commons licence and your intended use is not permitted by statutory regulation or exceeds the permitted use, you will need to obtain permission directly from the copyright holder. To view a copy of this licence, visit http://creativecommons.org/licenses/by/4.0/.

\section{References}

1. Johnson EM (2009) Rare and emerging Candida species. Curr Fungal Infect Rep 3(3):152-159

2. Oxman DA, Chow JK, Frendl G, Hadley S, Hershkovitz S, Ireland P, McDermott LA, Tsai K, Marty FM, Kontoyiannis DP, Golan Y (2010) Candidaemia associated with decreased in vitro fluconazole susceptibility: is Candida speciation predictive of the susceptibility pattern? J Antimicrob Chemother 65(7):1460-1465. https://doi.org/10.1093/jac/dkq136

3. Lewis MAO, Williams DW (2017) Diagnosis and management of oral candidosis. Br Dent J 223(9):675-681. https://doi.org/10. 1038/sj.bdj.2017.886

4. Gutierrez J, Morales P, Gonzalez MA, Quindos G (2002) Candida dubliniensis, a new fungal pathogen. J Basic Microbiol 42(3):207227. https://doi.org/10.1002/1521-4028(200206)42:3\%3c207:: AID-JOBM207\%3e3.0.CO;2-C

5. Sullivan DJ, Westerneng TJ, Haynes KA, Bennett DE, Coleman DC (1995) Candida dubliniensis sp. nov.: phenotypic and molecular characterization of a novel species associated with oral candidosis in HIV-infected individuals. Microbiology 141(Pt 7):1507-1521. https://doi.org/10.1099/13500872-141-7-1507

6. Sullivan DJ, Moran GP, Pinjon E, Al-Mosaid A, Stokes C, Vaughan C, Coleman DC (2004) Comparison of the epidemiology, drug resistance mechanisms, and virulence of Candida dubliniensis and Candida albicans. FEMS Yeast Res 4(4-5):369-376. https://doi.org/10.1016/S1567-1356(03)00240-X

7. Coleman DC, Moran GP, McManus BA, Sullivan DJ (2010) Mechanisms of antifungal drug resistance in Candida dubliniensis. Future Microbiol 5(6):935-949. https://doi.org/10.2217/fmb. 10.51

8. Moran GP, Sullivan DJ, Henman MC, McCreary CE, Harrington BJ, Shanley DB, Coleman DC (1997) Antifungal drug 
susceptibilities of oral Candida dubliniensis isolates from human immunodeficiency virus (HIV)-infected and non-HIV-infected subjects and generation of stable fluconazole-resistant derivatives in vitro. Antimicrob Agents Chemother 41(3):617-623

9. Borg-von Zepelin M, Niederhaus T, Gross U, Seibold M, Monod M, Tintelnot K (2002) Adherence of different Candida dubliniensis isolates in the presence of fluconazole. AIDS 16(9):1237-1244

10. Lundstrom IM, Anneroth GB, Holmberg K (1984) Candida in patients with oral lichen planus. Int J Oral Surg 13(3):226-238. https://doi.org/10.1016/s0300-9785(84)80008-3

11. Zeng X, Hou X, Wang Z, Jiang L, Xiong C, Zhou M, Chen Q (2009) Carriage rate and virulence attributes of oral Candida albicans isolates from patients with oral lichen planus: a study in an ethnic Chinese cohort. Mycoses 52(2):161-165. https://doi.org/ 10.1111/j.1439-0507.2008.01554.x

12. Jainkittivong A, Kuvatanasuchati J, Pipattanagovit P, Sinheng W (2007) Candida in oral lichen planus patients undergoing topical steroid therapy. Oral Surg Oral Med Oral Pathol Oral Radiol Endod 104(1):61-66. https://doi.org/10.1016/j.tripleo.2006.10. 024

13. Ismail SB, Kumar SK, Zain RB (2007) Oral lichen planus and lichenoid reactions: etiopathogenesis, diagnosis, management and malignant transformation. J Oral Sci 49(2):89-106. https://doi. org/10.2334/josnusd.49.89

14. Arora S, Verma M, Gupta SR, Urs AB, Dhakad MS, Kaur R (2016) Phenotypic variability and therapeutic implications of Candida species in patients with oral lichen planus. Biotech Histochem 91(4):237-241. https://doi.org/10.3109/10520295.2015. 1127425

15 Artico G, Freitas RS, Santos Filho AM, Benard G, Romiti R, Migliari DA (2014) Prevalence of Candida spp., xerostomia, and hyposalivation in oral lichen planus-a controlled study. Oral Dis 20(3):e36-e41. https://doi.org/10.1111/odi.12120

16. Masaki M, Sato T, Sugawara Y, Sasano T, Takahashi N (2011) Detection and identification of non-Candida albicans species in human oral lichen planus. Microbiol Immunol 55(1):66-70. https://doi.org/10.1111/j.1348-0421.2010.00285.x

17. Marable DR, Bowers LM, Stout TL, Stewart CM, Berg KM, Sankar V, DeRossi SS, Thoppay JR, Brennan MT (2016) Oral candidiasis following steroid therapy for oral lichen planus. Oral Dis 22(2):140-147. https://doi.org/10.1111/odi.12399

18. Krogh P, Hald B, Holmstrup P (1987) Possible mycological etiology of oral mucosal cancer: catalytic potential of infecting Candida aibicans and other yeasts in production of $\mathrm{N}$-nitrosobenzylmethylamine. Carcinogenesis 8(10):1543-1548. https://doi.org/ 10.1093/carcin/8.10.1543

19. Marttila E, Bowyer P, Sanglard D, Uittamo J, Kaihovaara P, Salaspuro M, Richardson M, Rautemaa R (2013) Fermentative 2-carbon metabolism produces carcinogenic levels of acetaldehyde in Candida albicans. Mol Oral Microbiol 28(4):281-291. https://doi.org/10.1111/omi.12024

20. Silverman S Jr, Migliorati CA, Epstein JB, Samaranayake LP (1990) In: Samaranayake LP, MacFarlane TW (eds) Laboratory diagnosis of oral candidosis, 1st edn. Wright, London, pp 213-237

21. Coronado-Castellote L, Jiménez-Soriano Y (2013) Clinical and microbiological diagnosis of oral candidiasis. J Clin Exp Dent 5(5):e279-286. https://doi.org/10.4317/jced.51242

22. Mehdipour M, Taghavi Zenouz A, Hekmatfar S, Adibpour M, Bahramian A, Khorshidi R (2010) Prevalence of Candida species in erosive oral lichen planus. J Dent Res Dent Clin Dent Prospects 4(1):14-16. https://doi.org/10.5681/joddd.2010.004

23. Krogh P, Holmstrup P, Thorn JJ, Vedtofte P, Pindborg JJ (1987) Yeast species and biotypes associated with oral leukoplakia and lichen planus. Oral Surg Oral Med Oral Pathol 63(1):48-54. https://doi.org/10.1016/0030-4220(87)90339-2
24. Coco BJ, Bagg J, Cross LJ, Jose A, Cross J, Ramage G (2008) Mixed Candida albicans and Candida glabrata populations associated with the pathogenesis of denture stomatitis. Oral Microbiol Immunol 23(5):377-383. https://doi.org/10.1111/j.1399-302X. 2008.00439.x

25. Muadcheingka T, Tantivitayakul P (2015) Distribution of Candida albicans and non-albicans Candida species in oral candidiasis patients: Correlation between cell surface hydrophobicity and biofilm forming activities. Arch Oral Biol 60(6):894-901. https:// doi.org/10.1016/j.archoralbio.2015.03.002

26. Loreto ES, Scheid LA, Nogueira CW, Zeni G, Santurio JM, Alves SH (2010) Candida dubliniensis: epidemiology and phenotypic methods for identification. Mycopathologia 169(6):431-443. https://doi.org/10.1007/s11046-010-9286-5

27. Mahelova M, Ruzicka F (2017) Methods of Candida dubliniensis identification and its occurrence in human clinical material. Folia Microbiol (Praha) 62(5):401-408. https://doi.org/10.1007/ s12223-017-0510-2

28. Al-Karaawi ZM, Manfredi M, Waugh ACW, McCullough MJ, Jorge J, Scully C, Porter SR (2002) Molecular characterization of Candida spp. isolated from the oral cavities of patients from diverse clinical settings. Oral Microbiol Immunol 17(1):44-49. https://doi.org/10.1046/j.0902-0055.2001.00081.x

29 Pereira TdSF, Silva Alves JdFC, Gomes CC, Rocha do Nascimento A, Stoianoff MAdR, Gomez RS (2014) Kinetics of oral colonization by Candida spp during topical corticotherapy for oral lichen planus. J Oral Pathol Med 43(8):570-575. https:// doi.org/10.1111/jop.12174

30. Kragelund C, Kieffer-Kristensen L, Reibel J, Bennett EP (2013) Oral candidosis in lichen planus: the diagnostic approach is of major therapeutic importance. Clin Oral Investig 17(3):957965. https://doi.org/10.1007/s00784-012-0757-6

31. Samaranayake LP (1990) In: Samaranayake LP, MacFarlane TW (eds) Host factors and oral candidosis, 1 st edn. Wright, London, pp 66-105

32. Williams DW, Kuriyama T, Silva S, Malic S (2000) Lewis MA (2011) Candida biofilms and oral candidosis: treatment and prevention. Periodontol 55(1):250-265. https://doi.org/10.1111/j. 1600-0757.2009.00338.x

33. Ellepola A, Samaranayake L (2001) Inhalational and topical steroids, and oral candidosis: a mini review. Oral Dis 7(4):211216. https://doi.org/10.1034/j.1601-0825.2001.70402.x

34. Shimizu C, Kuriyama T, Williams DW, Karasawa T, Inoue K, Nakagawa K, Yamamoto E (2008) Association of oral yeast carriage with specific host factors and altered mouth sensation. Oral Surg Oral Med Oral Pathol Oral Radiol Endodontol 105(4):445-451. https://doi.org/10.1016/j.tripleo.2007.11.030

35. Millsop JW, Fazel N (2016) Oral candidiasis. Clin Dermatol 34(4):487-494. https://doi.org/10.1016/j.clindermatol.2016.02. 022

36 Ellepola ANB, Khan ZU (2019) Impact of cigarette smoke condensate on adhesion-related traits and hemolysin production of oral Candida dubliniensis isolates. Mycopathologia. https://doi. org/10.1007/s11046-11019-00411-11041

37. Soysa NS, Ellepola ANB (2005) The impact of cigarette/tobacco smoking on oral candidosis: an overview. Oral Dis 11(5):268273. https://doi.org/10.1111/j.1601-0825.2005.01115.x

38. Sanitá PV, Pavarina AC, Giampaolo ET, Silva MM, Mima EG, Ribeiro DG, Vergani CE (2011) Candida spp. prevalence in well controlled type 2 diabetic patients with denture stomatitis. Oral Surg Oral Med Oral Pathol Oral Radiol Endod 111(6):726-733. https://doi.org/10.1016/j.tripleo.2011.02.033

39. Zomorodian K, Haghighi NN, Rajaee N, Pakshir K, Tarazooie B, Vojdani M, Sedaghat F, Vosoghi M (2011) Assessment of Candida species colonization and denture-related stomatitis in 
complete denture wearers. Med Mycol 49(2):208-211. https:// doi.org/10.3109/13693786.2010.507605

40. Hertel M, Schmidt-Westhausen AM, Strietzel FP (2016) Local, systemic, demographic, and health-related factors influencing pathogenic yeast spectrum and antifungal drug administration frequency in oral candidiasis: a retrospective study. Clin Oral Investig 20(7):1477-1486. https://doi.org/10.1007/ s00784-015-1631-0

41. Silva S, Henriques M, Martins A, Oliveira R, Williams D, Azeredo J (2009) Biofilms of non-Candida albicans Candida species: quantification, structure and matrix composition. Med Mycol 47(7):681-689. https://doi.org/10.3109/1369378080 2549594

42. He XY, Meurman JH, Kari K, Rautemaa R, Samaranayake LP (2006) In vitro adhesion of Candida species to denture base materials. Mycoses 49(2):80-84. https://doi.org/10.1111/j.1439-0507. 2006.01189.x

43. Bokor-Bratic M, Cankovic M, Dragnic N (2013) Unstimulated whole salivary flow rate and anxiolytics intake are independently associated with oral Candida infection in patients with oral lichen planus. Eur J Oral Sci 121(5):427-433. https://doi.org/10.1111/ eos. 12073

44. Scully C, Bagan JV (2004) Adverse drug reactions in the orofacial region. Crit Rev Oral Biol Med 15(4):221-239. https://doi.org/10. 1177/154411130401500405
45. Wolff A, Joshi RK, Ekström J, Aframian D, Pedersen AM, Proctor G, Narayana N, Villa A, Sia YW, Aliko A, McGowan R, Kerr AR, Jensen SB, Vissink A, Dawes C (2017) A guide to medications inducing salivary gland dysfunction, xerostomia, and subjective sialorrhea: a systematic review sponsored by the world workshop on oral medicine VI. Drugs R D 17(1):1-28. https://doi.org/10. 1007/s40268-016-0153-9

46. Bergdahl M, Bergdahl J (2000) Low unstimulated salivary flow and subjective oral dryness: association with medication, anxiety, depression, and stress. J Dent Res 79(9):1652-1658. https://doi. org/10.1177/00220345000790090301

47. Weerasuriya N, Snape J (2008) Oesophageal candidiasis in elderly patients: risk factors, prevention and management. Drugs Aging 25(2):119-130. https://doi.org/10.2165/00002512-20082 5020-00004

Publisher's note Springer Nature remains neutral with regard to jurisdictional claims in published maps and institutional affiliations. 